\title{
University to night school, to graduate school, to training, to short course
}

\section{E. Fjarlie}

E. J. Fjarlie, "University to night school, to graduate school, to training, to short course," Proc. SPIE 9666, 11th Education and Training in Optics and Photonics Conference, 96661 ( (5 June 2009); doi: 10.1117/12.2208032

SPIE Event: Eleventh International Topical Meeting on Education and Training in Optics and Photonics, 2009, St. Asaph, United Kingdom 


\title{
University to night school, to graduate school, to training to short course
}

\author{
EJ Fjarlie \\ EJ Fjarlie, PEnga; Kingston, ON, Canada, K7K 6X2
}

\begin{abstract}
Observations from teaching and learning over a 50 year span in various venues are made. The emphasis is on optics/photonics, but excursions are made into lower frequency electro-magnetic waves. Night-school students have priorities and necessities that are different from full-time students, visiting foreign students have another goal, graduate students (and their supervisors!) have a focus on research, contractual programs and short-course participants have specific interests in equipment and projects. The requirements place different demands on timing, assignments, emphasis, etc, for the lecture/ teaching/ laboratory aspects of the programs. Lessons that have been learned over the years are outlined.
\end{abstract}

\section{KEYWORD LIST}

military, radiometric equation, supply teaching, professional courses, cultural difference, certificates, virtual experiments, Satellite Earth Station, weather satellite, co-op students, political decision

\section{INTRODUCTION}

This discussion is a career outline as it applies to ETOP. Some detail is given of specific courses and concepts on how a given topic was presented, and provides ideas that have worked for motivation, some that have not, some omissions, and some guidance and hints that may be useful for others. It is a kind of confession with suggestions. The programs are disparate, had different requirements, entailed varying effort, had mixes of lectures, demonstrations, and laboratory work, varied as to assignments and examinations as well as in mathematics content, and enjoyed different results. The order is not chronological, but by topic. Now ending a career as an optical engineering consultant ${ }^{a}$ there have been many opportunities to take note of what works and what does not.

a) Most recently: Subject Matter Expert, Maritime Helicopter Project, CFB Ottawa(North), DND, Ottawa, ON (2002-06)

\section{TECHNOLOGY}

A few final-year science and engineering students as well as many graduate students find work in their career discipline as teaching assistants, TAs. Individuals desire to supplement their income; the department needs the TA to advance the programs. Few TAs receive instruction as to how to teach or organize. The TA is an on-the-job trainee ${ }^{b}$ who is to demonstrate technology and provide some instruction. TAs are under stress to mark weekly reports, maintain good order, set up new experiments, and show how to overcome difficulties. For most TAs this is the first introduction to the teaching/education process.

The TA is often the only person with whom the student has close contact; the professor is a face at the front of the lecture theatre who appears for 45 to 50 minutes, two or three times a week. A student may wish to be involved in discussion, but there is little time opportunity. Hiring a TA is a value judgment. It must not be the hiring of a body to fill the position. To work as a TA is also a value judgment; the TA has to balance work with personal study. Not enough care is taken in choosing the TA nor by the TA in applying for the job. 
A mistake that some universities make in presenting any laboratory program is to use antiquated equipment. This may be financially driven, or perhaps is a mistaken belief that the student should have an indication of the difficulties of experimentation. The expectation is that the student will develop patience, appreciate the work, and gain understanding. The reality is that it foments frustration, because results can be unconvincing. The student not needing to proceed beyond the initial optics course gets an incorrect impression of the discipline. Virtual demonstrations provide a far more flexible, smart, and illustrative picture.

Military personnel require technical instruction in their various disciplines. Lessons in radio communications ${ }^{c}$ were offered to a group of reserve airmen one night per week over a two-year span. A degree in engineering, PG work in progress, and a commission as an aircrew officer, qualified me as having some knowledge greater than the students'. Since my knowledge of aircraft radios was minuscule, the lectures were limited to basics: resistance, capacitance, inductance, Ohm's law, and some circuitry. Like many new instructors, my mistake was to try to cover a year's material in the first few lectures! Like all neophytes, the class wanted to understand the complexities of radio without knowing anything about fundamentals. The class was tolerant in the hope that the next week would see the resolution of everything! The goal was clear, but the delivery was murky. Such programs must be given by an experienced instructor in order to have value. Training for technicians has to change as the technology advances.

[b] Physics Department, University of British Columbia, Vancouver, BC, (1954-56); Physics Department, University of Saskatchewan, Saskatoon, SK, (1959-63); Royal Military College of Canada, Kingston, ON, (1977-98); Royal Military College of Science, Shrivenham, UK, (1983-84); Queen's University, Kingston, ON, (1993-94)

[c] Royal Canadian Air Force, \#442 Squadron, Station Sea Island, Vancouver, BC, (1955-57)

An experienced instructor/operator can impart new techniques for others to keep abreast. My hiring should never have happened, but the squadron was anxious to have 'a body' as communications officer.

Many community colleges and trade schools offer specific training programs. Our local college had found itself without an instructor for their program in heating, ventilating, and air conditioning. Several of us volunteered to fill the hiatus ${ }^{d}$; each presented a number of classes in applied thermodynamics. Four professors used to explaining the mysteries of entropy, enthalpy, etc, found themselves teaching as a committee, unable to make use of mathematical arguments! While commendable in intent, there was little opportunity for coordination-hurried corridor meetings were the norm! The effort was full of compromise. What the students needed was a 'how to' course, not the 'why' or generalization course they received. The saving grace was that the program had no formal examinations; assignments could be repeated until correctly done. The students survived, but we dared not ask their opinion of the course!

\section{UNDERGRADUATE PROGRAMS}

Untried lecturers can be asked to do many things:

1) While working on PG programs, many of us have been asked to fill-in for a supervisor; that is to "supply" teach, or substitute, for one or two lectures. The raison d'etre is to give the professor some relief or perhaps to maintain 'momentum' because the professor is away, or possibly because of illness; the PG student gets a little experience ${ }^{e}$. Students do not like it, the new face presents a new attitude, the professor does not like it, there is uncertainty whether the material was covered properly; the PG substitute does not like it, he or she is often not paid, and there is uncertainty whether the 'pitch' is at the right level. Unless a significant number of classes would be missed, it is better to cancel the lectures.

2) In large urban centres, the population base allows for classes in the evenings. Courses that were given by me working as a part-time lecturer three nights per week over six years included: optics, heat, atomic physics, fluid dynamics, and thermodynamics to physics students ${ }^{f}$ and electricity and magnetism to engineering students ${ }^{g}$. Laboratories operated without TAs. Students went to assigned work stations, an operator activated the station and the student had a fixed time to carry out the experiment. if not completed, a new time was scheduled for the lab, but marks were then lost from the report. This program was successful, but the stress level is high; one of my first students was arrested for murder during the term, and a group in a different program, mistaken in their inferences about racial discrimination, vandalized the computing facilities! 
[d] Heating/Ventilating,Air Conditioning Technologist Program, St Lawrence College, Kingston, ON, (1993)

[e] Physics Department, University of Saskatchewan, Saskatoon, SK, (1963-64)

[f] Physics Department, Sir George Williams University (now part of Concordia U), Montreal, QC, (1966-71)

[g] Physics Department, Sir George Williams University (now part of Concordia U), Montreal, QC, (1972)

3) Exchange programs exist for the opportunities for cross-pollination of teaching staff. One such

exchange, into a mechanical engineering program ${ }^{h}$, found me trying to find a niche in optics research in the physics department, but to no avail. My ME 'label' at that time was the impediment. The exchange did lead to students coming to the Royal Military College, RMC, for work periods as research assistants in following years. To augment their UK incomes, a grant was provided from my research funds.

4) A sabbatical year was spent in France fitting into an undergraduate physics program ${ }^{i}$ and also into a PG engineering program ${ }^{j}$. Language was French for the undergraduates, English for the PGs. The subject matter, instrumentation in the former case and electro-optics in the latter, was a mix of practical information with the necessary mathematics. Laboratory work was missing in these programs.

\section{TRAINING FOR SPECIFIC EQUIPMENT}

Several programs were organized for six-months training for engineers from India ${ }^{k}$ and Pakistan ' to operate and maintain Satellite Earth Stations, The contracts were 'turn-key' to include: ground-breaking and construction at the site, a 30m diameter 'dish' steerable antenna, a mix of sub-systems--some assembled, some fabricated--with integration in Canada. Since the equipment was being assembled at the same time as the participants were being trained, visits were arranged to view working Satellite Earth Stations in Canada. A training program for technicians was organized in Montreal to be delivered in Islamabad.

The cultural backgrounds of the participants had to be taken into account. Those of the Muslim faith needed a satisfactory room for daily prayer that was close to the lecture room. Social interactions were scheduled on how to function in Canadian society and on winter conditions. Classes were given by company engineers who were excellent at organizing and supervising the fabrication and assembly of the equipment, but they were not teachers. Laboratory work, while not refused, was awkwardly carried out; the senior personnel insisted that their juniors on the program do the assignments and measurements; that is a hierarchy existed within the course. Examinations would have fomented rebellion, but multiple choice tests were organized. A 'certificate' was issued at the end for all to take back to their home countries. These were operators, not particularly interested in 'why', but in 'how to'. When the separation of East and West Pakistan occurred, the six-month program was about $1 / 2$ completed. It was the maturity of the participants that allowed completion even though those from (now) Bangladesh knew that they would not receive the second Earth Station.

[h] Mechanical Engineering Department, Royal Military College of Science, Shrivenham, Wilts, UK, (1983-84)

[i] Physics Department, Universit? Louis Pasteur, Strasbourg, FR, (1989-90)

[j] ENSAIS, Strasbourg, FR, (1989-90)

[k] R\&D Laboratories, RCA Ltd, Montreal, QC, (1968)

[l] R\&D Laboratories, RCA Ltd, Montreal, QC, (1969-70)

A one-week course detailing use of laser anemometry equipment was joined ${ }^{\mathrm{m}}$. There were about 20 participants from eight or nine countries The course included many details on advanced systems than was needed; the company's desire to try to sell more equipment outweighed the specificity. This course seemed to be a clone of a university course that had developed into a book, but the book was hampered by its unusual course-slide description format. Both the book and course are examples of multi-purpose efforts that fail.

\section{GENERAL PROGRAMS}

An opportunity was uncovered to enhance the education of foreign students taking engineering courses at various Canadian universities. Because of Canadian law relating to visitors, such students were not allowed to work in Canada; their sponsor, the Canadian International Development Agency, was keen to provide such an opportunity; two programs were organized for $2^{\text {nd }}$ and $3^{\text {rd }}$ year students at different Canadian universities. 
Each program was of eight weeks duration, eight hours per day.

The first was to construct a weather-satellite tracking station ${ }^{n}$. The effort used commercial kits to construct the various sub-systems - receiver, amplifier, power supply, and test equipment; the antenna and its tracking system were built from 'scratch'. The students were from Uganda, Kenya, Jamaica, and Taiwan. What they lacked in background was made up by desire. They came together to work on a project with a goal. A side benefit was the development of leadership skills as the project advanced. My education into the 'real world' came about when four of them disappeared suddenly because of direct death threats to them from their home country because they were getting an education!

The second saw the presentation of lectures and labs on: laser theory, IR detectors, radiometry, basic optics, electronic equipment, and communication fundamentals ${ }^{\circ}$. The students were from Viet Nam, and Singapore. The program included visits to nearby government and industrial laboratories as well as many demonstrations of state-of-the-art equipment, techniques, and measurements. This project was too similar to a university lecture and laboratory program; the desired object of work experience was not achieved.

It was natural later to hire Canadian co-op students from Canadian universities to work as research assistants. Because of the rules associated with such hirings, the match between student and job is not always exact. In addition, when there is not enough financial resources to entice permanent staff, a compromise is required. The short term employee is usually a compromise worker.

[m] DISA (now Dantek Corp), Copenhagen, DK, (1982)

[n] R\&D Laboratories, RCA Ltd, Montreal, QC, (1971)

[o] R\&D Laboratories, RCA Ltd, Montreal, QC, (1973)

The co-op students $^{p, q}$ (as well as others marginally qualified) have to be prepared to accept a lower wage. There is a significant loss of time on the part of the contractor-as much as 1/4 time for some work and both supervisor and assistant have to be prepared to make concessions.

\section{POST GRADUATE PROGRAMS}

Work at the Royal Military College of Canada, RMC, started with a research program on liquid crystal light valves $^{r}$, but it was evident that in a military university a program in electro-optical systems: FLIR, LWR, SAR, LLTV, etc, would be easier to sell. The most important order of business for any researcher is to learn what the interests of the potential sponsor are likely to be! Eventually diffractive elements, laser anemometry, and fibre-optic sensing, were added to the program ${ }^{1}$ The label 'optical engineering' was difficult to use because it had no obvious visibility at RMC; my faculty appointmtne was to an ME department. Optics and mechanical design may be attached at some universities in Europe and Asia, but in North America it is EE or physics where optics/photonics, ETOP, is found. What is most often forgotten is that optical systems have perhaps $50 \%$ of their total cost associated with mechanical design. The program made extensive use of spectroscopy, radiometry, and detector technology with many examples of active and passive systems and devices.

There were 14 Canadian Forces officers who received their Master's degree, and one civilian PhD degree; one person withdrew. The PG students entered the program following one or two postings in their military career. The students are three to six years older that what is expected at a civilian university. All students are under full employment; financial support is a non-issue. Most have families, their maturity is an asset, but the difficult part is that all have been out of academics for a considerable time. The program accepted PG students from different departments: physics, EE, ME, applied physics, and computer science. The program had to start with an 'umbrella' course to review many concepts. However, it was a non-starter to begin with basics, these participants needed to see where 'they were going' from the beginning. The radiometric equation was the crutch for developing the program:

$$
P_{\text {rcd }}=N_{\lambda} \cdot r_{\lambda} \cdot A_{s} \cdot\left(A_{d} / R^{2}\right) \cdot T_{\text {atmos }} \cdot T_{o}
$$


Here: $N_{\lambda}$ is the radiance, $r_{\lambda}$ is the reflectivity of the source or target, $A_{s}$ is the cross section of the source, $\left(A_{c} / R^{2}\right)$ is the solid angle for the receiver, $A_{c}$ is the area of the collector, $R$ is the range or distance between source and collector, $\mathrm{T}_{\mathrm{atmos}}$ is the atmospheric transmittance, and $\mathrm{T}_{\mathrm{o}}$ is the transmittance of the optics.

[p] University of Waterloo, Kitchener, ON, (1980-83)

[q] University of Sherbrooke, Sherbrooke, QC, (1988-89)

[r] Mechanical Engineering Department, RMC, Kingston, ON, (1976-2003)

Hidden in the radiance term is the emissivity (or reflectivity if is is passive). Students could see the significance of reflectivity, of solid angle, of atmospheric transmittance, of collector aperture, etc, and became interested in learning the detail associated with each of these parameters. The lectures were supplemented by several references $2,3,4,5$.

As this PG program became more established, scholars from other countries wrote to ask for Post Doctoral attachments as Research Associates. Funds were available, but RMC was not comfortable when a request came from a researcher in a country that was on DND's short list of places to avoid. Politics took precedence.

\section{SHORT COURSES}

As the PG program became popular, it became obvious at National Defense Headquarters, NDHQ, that others should have more than a rudimentary knowledge in ETOP. The Electro-Optics Short Course, duration two weeks ${ }^{s}$. was organized for DND personnel and provided once per year at no cost ${ }^{6}$. This attracted 19 to 22 serving officers, Captain to Lt Colonel, including two or three civilians each year to come to RMC. Special lecturers - some from industry, some from government laboratories, some from overseas-were found through personal contacts to present specific parts of the course. All were pleased to come, also at no cost for this was an opportunity to contact individuals who would be playing a key role in different departments in NDHQ. The program was in place for nine years. Two editions of notes were written and issued to all participants ${ }^{7}$.

The Electro-Optics Short Course ended in 1996 with NDHQ suggesting that the two weeks be compressed into three days (or less)--an impossible task: 'A sherry glass cannot hold the contents of a bottle of scotchsingle malt at that'! It is my view that the Electro-Optics Short Course 'died' because of a lack of visibility; that is, being a part of an ME department was not seen as having value within NDHQ. Due diligence had not been done to publicize and emphasize the utility of the program.

During a sabbatical ${ }^{\mathbf{t}}$, a different short course in Electro-Optics, 1/2- day per week for three months, was developed for technologists, for people who had some knowledge, but little specific optics background. There were 12 participants, but their presence depended on their on-going work; average attendance was six--not always the same six. Such courses need to be mandatory, but there was a lack of focus for some and not enough for others on this one. The notes ${ }^{7}$ were available in French, but were not specific enough.

[s] Electro-Optics Short Course, RMC, Kingston, ON, (1988-96)

[t] Short Course in Electro-Optics, Defense Research Establishment Valcartier, Courcellette, QC, (1996)

The Applied Military Science Department, AMS, was started at RMC with the purpose to repatriate a program previously given at RMCS for land element officers to upgrade their skills in the use and appreciation of vehicles, artillery, ammunition, and the sub-systems for control, and the appreciation of safety aspects ${ }^{u}$. Known at RMC as the Land Forces Technical Staff Program, it lacked lectures in optical systems that included laser systems, thermal imaging, low light level TV, sighting mechanisms, etc. The lectures were provided at no cost, an allotment of 27 periods was available ${ }^{8}$. The participants needed notes; the only notes available were those of the Electro-Optics Short Course ${ }^{7}$. It is my understanding they are still in use. Being a mix of participants--arts and business, with a few science and engineering graduates--mathematics had to be downplayed, but could not always be avoided. 
A one-half day professional course on diffractive elements, was presented at two ICAPT(SPIE, OSA, IEEE) meetings $\mathrm{v}, \mathrm{w}$. Participants at professional meetings, having paid for a course, are demanding, but the presenters can be reticent about giving away all 'their secrets'. There are mixed feelings on the part of the presenter, when such a 'professional course' is offered. To my knowledge, there are few professional courses in optics/photonics that have been expand into text books, with one notable exception ${ }^{9}$.

\section{FURTHER COMMENTARY}

Some of the optics/photonics problems that have been noticed follow:

a) Because optics is an old study, fundamentals tend to be accepted without full understanding. The true nature of a concept may be a problem for years because the 'little knowledge has become dangerous'; the mis-understanding has continued to be accepted.

b) sign conventions for image orientation, right/left and up/down, are readily accepted, but are forgotten when multiple elements are involved. Further problems are created when polarization is considered.

c) the terms aberrations and diffraction are often interchanged-their proper meaning is lost.

d) the distinctions between time constant, time of response, and rise time, is not appreciated.

e) diffraction is a difficult topic without the use of Fourier Transforms. The mathematics is essential. Showing the 'pretty pictures' to neophytes without expressing scale is useless. Far field and near field diffraction needs more discussion.

f) spectroscopic displays are beautiful; they are still beautiful even though the spectrometer/ spectrograph may be poorly aligned. The need for proper laboratory alignment technique can be lost-the beauty hides the difficulties.

[u] Applied Military Science, Land Forces Technical Staff Program, RMC, Kingston, ON, (1996-2003)

[v] Diffractive Optical Elements, ICAPT, Montreal, QC, (1998)

[w] Diffractive Optical Elements, ICAPT, Ottawa, ON, (2000)

g) amplitude and phase are studied abstractly; not enough time is spent to understand why detector output depends on power, and the information about amplitude and phase is lost.

\section{CONCLUSIONS}

i) New faculty, be they lecturers, readers, or professors, should be required to 'sign off' on a basic instruction package obtained from the Dean's office before to begin lecturers, TA's must receive a modicum of instruction - a day at the least. Leaving the individual to use his or her initiative is asking for 'trouble'.

ii) Burying one program inside another does no one a service.

lii) Consistency in the presentation of lectures is paramount-consistency in use of symbols, in the logic, in the schedule, in the marking, in following the outline, and consistency in the treatment of students.

iv) Organization cannot be emphasized enough.

v) Language skills are poor. Associated with this is that too many marginal students are accepted into programs. At least $1 / 5$ of one's career time is spent writing reports, the report must convey information.

vi) To be topical or fashionable without effective presentation of the fundamentals is a waste of time.

vii) Teaching by committee is anethema. Furthermore, multi-purpose activities are not effective.

viii) Supply teaching for a couple of lectures is not helpful. Supply teaching is sensible when the substitute can set the pace over an extended period so that the student is comfortable.

ix) Specific topics want specific answers -- not generalizations, nor a development of fundamentals.

x) Certificates or 'diplomas' without proper examinations only indicate attendance. Institutions accredited by national or provincial bodies should be the only issuers of documents associated with learning.

xi) Not enough effort is spent trying to understand and appreciate student concerns. 


\section{REFERENCES}

[1] EJ Fjarlie, "Post Graduate Program in Optics \& Photonics", ETOP 2007 Conference, SPIE, Ottawa, ON, (June, 2007)

[2] FA Jenkins \& HE White, Fundamentals of Optics, $2^{\text {nd }}$ ed, McGraw Hill, New York, NY, (1950)

[3] BEA Saleh \& MC Teich, Fundamentals of Photonics, John Wiley, New York, NY, (1991)

[4] WJ Smith, Modern Optical Engineering, McGraw Hill, New York, NY, (‘ 1966)

[5] JS Accetta \& DL Shumaker eds, The Inf;rared \& Electro-Optical Systems Handbook, 8 volumes, ERIM \& SPIE, Ann Arbour, MN, \& Bellingham, WA, (1993)

[6] EJ Fjarlie, "Electro-Optics Short Course", ETOP 2007 Conference, SPIE, Ottawa, ON, (June, 2007)

[7] EJ Fjarlie, Electro-Optics, RMC Kingston, June, (1988); became: Electro-Optics, $2^{\text {nd }}$ ed, RMC Kingston, June, (1993); \& EJ Fjarlie, Electro-Optique (abr?g?), RMC, Kingston, ON, (1993)

[8] EJ Fjarlie, "An Optics \& Photonics Program: Buried", ETOP 2007 Conference, SPIE, Ottawa, ON, (June, 2007)

[9] G Parent jr, \& BJ Thompson, Physical Optics Notebook, SPIE, Redondo Beach, CA, (1969); became: GO Reynolds, JB DeVelis, GB Parrent jr, \& BJ Thompson, The New Physical Optics Notebook: Tutorials in Fourier Optics, SPIE \& AIP, Bellingham, WA, \& New York, NY, (1989) 